\title{
KLF6 and TP53 mutations are a rare event in prostate cancer: distinguishing between Taq polymerase artifacts and true mutations
}

Laia Agell ${ }^{1,2,3}$, Silvia Hernández ${ }^{3}$ Silvia de Muga ${ }^{1,2,3}$, José A Lorente ${ }^{2,4}$, Núria Juanpere ${ }^{1,2}$, Raquel Esgueva ${ }^{1,2}$, Sergi Serrano ${ }^{1,2}$, Antoni Gelabert ${ }^{2,4}$ and Josep Lloreta ${ }^{1,3}$

${ }^{1}$ Department of Pathology, Hospital del Mar, Barcelona, Spain; ${ }^{2}$ Autonomous University of Barcelona, Barcelona, Spain; ${ }^{3}$ Department of Health and Experimental Sciences, Universitat Pompeu Fabra, Barcelona, Spain and ${ }^{4}$ Department of Urology, Hospital del Mar, Barcelona, Spain

\begin{abstract}
Krüppel-like factor 6 (KLF6) has been reported to act as a tumor suppressor gene involved in the regulation of the cell cycle by activating p21 in a p53-independent manner. Many studies suggest that KLF6 is inactivated by allelic loss and somatic mutation. However, there is a high variability in the reported frequency of mutations (from 1 to $55 \%$ ). TP53 also regulates the cell cycle through the activation of p21. In prostate cancer, the reported frequency of TP53 mutations ranges from 3 to $42 \%$. In all these reports, there is a considerable degree of methodological heterogeneity. Our aim was to determine the frequency of KLF6 and TP53 mutations in a welldefined group of prostate tumors with different stages and Gleason grades. The four exons of KLF6 and exons 4-9 of TP53 were studied in 103 cases, including 90 formalin-fixed, paraffin-embedded (FFPE) and 13 frozen samples. All tumors were analyzed through PCR and direct sequencing. All changes found were confirmed by a second independent PCR and sequencing reaction. For KLF6, mutation (E227G) was only detected in one tumor (1\%) and for TP53, three different mutations ( $\mathrm{L130H}, \mathrm{H} 214 \mathrm{R}$, and $\mathrm{Y234C}$ ) were detected in five tumors (5\%). This low mutation index is in keeping with recent papers on the subject. Our study strongly supports the notion that KLF6 and TP53 mutations are not frequent events in prostate cancer. When using FFPE tissues, it is mandatory to perform at least two independent rounds of PCR and sequencing to confirm mutations and exclude Taq polymerase-induced artifacts.
\end{abstract}

Modern Pathology (2008) 21, 1470-1478; doi:10.1038/modpathol.2008.145; published online 19 September 2008

Keywords: KLF6; TP53; prostate cancer; mutations; artifacts

Prostate cancer is the third most diagnosed cancer in Spain, ${ }^{1}$ and it is the second leading cause of cancer death in American men. ${ }^{2}$ Many different genes have been investigated for their potential roles in the development and progression of prostate cancer. ${ }^{3,4}$ Two of these genes are Krüppel-like factor $6(K L F 6)$ and TP53.

KLF6 is a transcription factor that interacts with DNA through three zinc-fingers in its $\mathrm{COOH}$ terminal domain. KLF6 belongs to the KLF family, a family that is broadly involved in cell differentiation, development, growth-related signal transduc-

Correspondence: Dr J Lloreta, MD, PhD, Department of Pathology, Hospital del Mar, Barcelona, Spain, Passeig Maritim 25-29, 08003 Barcelona, Spain.

E-mail: jlloreta@imas.imim.es

Received 30 May 2008; revised and accepted 6 August 2008; published online 19 September 2008 tion, cell proliferation, apoptosis, and angiogenesis. ${ }^{5}$ It has been suggested that $K L F 6$ could be involved in the regulation of the cell cycle by activating p21 in a p53-independent manner. ${ }^{6}$ This has been proven in several in vitro ${ }^{5}$ and in vivo assays. ${ }^{7}$ $K L F 6$ is believed to regulate cancer development and progression through the downregulation of the c-Jun oncoprotein ${ }^{8}$ and the activation of E-cadherin. ${ }^{9}$

The reported frequency of KLF6 mutations in different types of human cancer varies in the different published studies. ${ }^{10-29}$ In prostate cancer, four studies have analyzed the frequency of $K L F G$ mutations. ${ }^{6,30-32}$ In the first published study, Narla et $a l^{6}$ showed a very high frequency, $55 \%$, whereas in the following study, Chen et $a l^{30}$ obtained a lower frequency, around $15 \%$. The results of two recent reports provided frequencies of 0 and $1 \% \cdot{ }^{31,32}$ It should be noted that there were considerable 
differences in both the selected cohorts and the methodological approaches of these studies, which could, at least in part, explain the discrepancies in their results.

On the other hand, the reported frequency of loss of heterozigosity (LOH) in prostate cancer ranges from 28 to $77 \% .^{6,30}$ KLF6 promoter hypermethylation has been suggested as another possible inactivating mechanism, ${ }^{23,33-35}$ although according to some authors ${ }^{35}$ epigenetic alterations are not relevant in prostate cancer. Other studies have reported downregulation of KLF6 mRNA levels in hepatocellular carcinoma (HCC) and in lung cancer cell lines, as well as in prostate cancer cell lines. Decreased expression of KLF6 has been associated with poor prognosis in lung adenocarcinoma and prostate cancer. ${ }^{30,36-39}$

The role that KLF6 polymorphisms play in increasing the risk of developing prostate cancer is also controversial. Narla et $a l^{40}$ proposed that the presence of a germline single-nucleotide polymorphism (SNP) (IVS1 -27G $>$ A) in KLF6 could produce a splicing variant that would reduce the activation of p21. This polymorphism was associated with an increased risk for prostate cancer, ${ }^{40}$ but subsequent reports have shown contradictory results. ${ }^{32,41-44}$ Moreover, the R201R polymorphism of KLF6 has been reported to be of marginal importance in the predisposition of developing prostate cancer in a series of Finnish hereditary prostate cancer patients. ${ }^{45}$

The tumor suppressor gene TP53 acts in response to diverse cell stress situations by regulating target genes that induce cell-cycle arrest, apoptosis, senescence, DNA repair, or changes in metabolism. ${ }^{46}$ Like $K L F 6$, TP53 also regulates the cell cycle through the activation of p21. ${ }^{47}$ Mutations of TP53 occur in half of all human tumors. ${ }^{48}$ In prostate cancer, the reported frequency of mutation of TP53 in the different subgroups of prostate cancer is not well defined and ranges from 3 to $42 \% .^{2,49}$ The vast majority of TP53 mutations are missense point mutations ${ }^{50}$ that affect the DNA-binding domain. ${ }^{51}$ Many authors have used immunohistochemistry to evaluate the TP53 gene status, because some mutations could lead to p53 protein accumulation and immunohistochemical detection. Nevertheless, immunohistochemical overexpression does not necessarily indicate gene mutation. ${ }^{2}$ The amount of p53 protein in cells is determined mainly by the rate at which it is degraded through the activity of HMDM2. This process is related to a feedback loop, as p53 activates the transcription of HMDM2, and HMDM2 stimulates p53 degradation. ${ }^{52}$ It has also been reported that mutations in TP53 and CHEK2, a gene activated in response to various DNA-damaging agents, could be mutually exclusive in $25 \%$ of prostate tumors. ${ }^{53}$

From all these studies, it is obvious that, although KLF6 and TP53 are important in controlling the cell cycle, their involvement in the pathogenesis of prostate cancer is still controversial and uncertain. Thus, the main goal of the present study has been to elucidate the real frequency of KLF6 and TP53 mutations in a large group of prostate cancer samples classified by stage and Gleason grade and performing more than one round of PCR and sequencing, in order to avoid artifactual mutations and other methodological problems often encountered in formalin-fixed, paraffin-embedded (FFPE) samples.

\section{Materials and methods}

\section{Tumor Samples and Patients}

A total of 103 cases of prostate cancer selected from the files of the Department of Pathology at the Hospital del Mar in Barcelona, Spain, are the subject of this report. None of the patients received chemotherapy or hormonal therapy. A total of 90 of them were FFPE samples and 13 were frozen tissues, and none of them were matched. From these 103 cases, 77 were biopsy or prostatectomy specimens, 16 were tumors found at autopsy, so-called latent tumors, 8 were bone, and 2 lymph node metastases. Together, the Gleason grades of the biopsy, surgical, and autopsy specimens were: $\leq 6$ in 30 cases, 7 in 36 cases, and $\geq 8$ in 27 cases. In the surgical cases, TNM classification was performed whenever possible. Pathologic stage was pT2a in 6 cases, pT2b in 11 cases, pT3a in 16 cases, and pT3b in 2 cases. Prostatectomy specimens had been completely embedded, and with the tumor foci marked in every section, a map was obtained. Tumor volume was estimated by measuring the main diameters of the foci, considering the number of cross-sections in which they were present and the standard correction factor of 0.4. Many of the surgical cases with Gleason grade 6 had tumor volume greater than $0.5 \mathrm{~cm}^{3}$, and some had extraprostatic involvement or positive margins, features that excluded them from the standard definition of 'insignificant' prostate cancer (ie, organ-confined tumors, with tumor volume $0.5 \mathrm{~cm}^{3}$ and combined Gleason score 6 with no pattern 4). In a small subset of eight cases, found by needle biopsy and with Gleason $3+3$, no surgical treatment was performed, and therefore, we lacked any detailed staging information (Supplementary Table 1). Two prostate cell lines (PC3 and DU145) were also included as controls, TP53 and KLF6 mutations have been reported in these cell lines.

\section{KLF6 and TP53 Mutation Analysis}

Representative tumor areas containing at least $50 \%$ and usually around 90\% tumor cells were selected and manually microdissected from FFPE tissue sections or frozen tissues. Standard H\&E slides 
served as templates. DNA was extracted using the DNeasy Tissue Kit (Qiagen GmbH, Hilden, Germany) from two to three consecutive $10 \mu \mathrm{m}$ sections. To avoid the risk of PCR contamination, genomic DNA was extracted in a laboratory where neither PCR reactions were performed nor PCR products handled. KLF6 exons $1-4$ and TP53 exons 5-8 were amplified by PCR and directly sequenced in all cases. In the 13 cryopreserved samples, exons 4 and 9 of TP53 were also analyzed. As exon 2 of $K L F 6$ is very long, it was divided into three regions (2A, 2B, and 2C). The primer sequences and the size of the products used are shown in Table 1. PCR reactions were performed in a $25 \mu \mathrm{l}$ volume using $10-50 \mathrm{ng}$ of DNA, $0.2 \mu \mathrm{mol} / \mathrm{l}$ for each primer, $200 \mu \mathrm{mol} / \mathrm{l}$ deoxynucleotide triphosphates, $3.5 \mathrm{mmol} / \mathrm{l} \mathrm{MgCl}_{2}, 1 \times$ PCR II buffer, and $1.5 \mathrm{U}$ of Amplitaq Gold DNA Polymerase (PerkinElmer Applied Biosystems, Foster City, CA, USA). PCR conditions were as follows: $95^{\circ} \mathrm{C}(5 \mathrm{~min})$ for 1 cycle, $95^{\circ} \mathrm{C}(40 \mathrm{~s}), 63^{\circ} \mathrm{C}(40 \mathrm{~s}), 72^{\circ} \mathrm{C}(40 \mathrm{~s})$ for 40 cycles, and a final extension step of $72^{\circ} \mathrm{C}(5 \mathrm{~min})$. PCR products were separated by electrophoresis and visualized with ethidium bromide. Samples without DNA templates were included in all assays as negative controls. PCR products were purified using the Qiagen PCR purification kit (Qiagen, Crawley, UK) according to the manufacturer's protocol.

Table 1 Primer sequences, amplified fragment size, and primers' annealing temperatures for $K L F 6$ and TP53

\begin{tabular}{|c|c|c|c|}
\hline Exon & \multicolumn{2}{|c|}{ Primer sequence } & Fragment (bp) \\
\hline \multicolumn{4}{|l|}{ KLF6 } \\
\hline \multirow[t]{2}{*}{1} & $\mathrm{~F}$ & TCCGGGGAGACTTTCGGCTC & 204 \\
\hline & $\mathrm{R}$ & CTGTCGGCCGGCTGCGTTTA & \\
\hline \multirow[t]{2}{*}{$2 \mathrm{~A}$} & $\mathrm{~F}$ & AATCACGTGCCTTCTCTGGT & 289 \\
\hline & $\mathrm{R}$ & AAAGTTCCTCGGAGCTGTCA & \\
\hline \multirow[t]{2}{*}{$2 \mathrm{~B}$} & $\mathrm{~F}$ & GATGTCAGCAGCGAATCCTC & 251 \\
\hline & $\mathrm{R}$ & TCGCCATTTCCCTTGTCACC & \\
\hline \multirow[t]{2}{*}{$2 \mathrm{C}$} & $\mathrm{F}$ & GCGGGACTTCGGGGAAGCCA & 168 \\
\hline & $\mathrm{R}$ & AATGCAGTGGCGCCCACCAG & \\
\hline \multirow[t]{2}{*}{3} & $\mathrm{~F}$ & AGTGAAGACATGGGCTGCTT & 236 \\
\hline & $\mathrm{R}$ & GCATTGTCCTCAGGCACGTA & \\
\hline \multirow[t]{2}{*}{4} & $\mathrm{~F}$ & GCAAGGGATGGGAACCTAAC & 102 \\
\hline & $\mathrm{R}$ & CTCTCAGCCTGGAAGCCTTT & \\
\hline \multicolumn{4}{|l|}{ TP53 } \\
\hline \multirow[t]{2}{*}{4} & $\mathrm{~F}$ & САСССАТСТААСАGTСССССТTG & 307 \\
\hline & $\mathrm{R}$ & CTTGCACGGTCAGTTGCCCTGAG & \\
\hline \multirow[t]{2}{*}{5} & $\mathrm{~F}$ & TTTCAACTCTGTCTCСTTCСT & 250 \\
\hline & $\mathrm{R}$ & TGGGCAACCAGCCCTGTC & \\
\hline \multirow[t]{2}{*}{6} & $\mathrm{~F}$ & ACGACAGGGCTGGTTGCCCG & 200 \\
\hline & $\mathrm{R}$ & CTCCCAGAGACCCCAGTT & \\
\hline \multirow[t]{2}{*}{7} & $\mathrm{~F}$ & CCTCATCTTGGGCCTGTCTT & 210 \\
\hline & $\mathrm{R}$ & CCAGGGGTCAGCGGCAAGCA & \\
\hline \multirow[t]{2}{*}{8} & $\mathrm{~F}$ & CTGCCTCTTGCTTCTCTTTT & 190 \\
\hline & $\mathrm{R}$ & TCTCCTCCACCGCTTCTTGT & \\
\hline \multirow[t]{2}{*}{9} & $\mathrm{~F}$ & TTATGCCTCAGATTCACTTTTAT & 212 \\
\hline & $\mathrm{R}$ & TGAGCTGTTTTACCTGCAATTG & \\
\hline
\end{tabular}

$K L F 6$, Krüppel-like factor 6.
Non-autopsy cases were collected between 2000 and 2007, and autopsy cases were collected between 1993 and 2006. As most autopsy cases were relatively old, we checked the quality of the DNA by performing a previous control PCR. This multiplex PCR reaction consisted in the amplification of fragments of $100,200,300,400$, and $600 \mathrm{bp}$ of the $\beta$-actin gene.

Mutation analysis was performed by direct sequencing of purified PCR products with the Big Dye Terminator Kit v.3.1 (PerkinElmer Applied Biosystems) using an ABIPRISM 377 instrument (PerkinElmer Applied Biosystems). Each PCR product was sequenced in both forward and reverse directions. The same sets of primers used for PCR amplification were also used for sequencing. In all cases where a change was identified in the first PCR reaction $(42 \%$ of the cases for $K L F 6$ and $28 \%$ for TP53), an independent PCR amplification and sequencing was performed using the same DNA sample to verify the results. When we identified a new change in this second PCR, we performed a third, independent amplification and sequencing experiment. We considered there to be a confirmed mutation when we found the same change in two independent PCR and sequencing rounds. Taking the first, second, and third independent amplifications of KLF6 and TP53 together, the reproducibility of our mutational analysis was about $97 \%$. In some cases, the mutational study could not be completed due to a failure of PCR reaction or small sample size. For this reason, the KLF6 exon 2A could not be amplified in 10 cases, exon $2 \mathrm{~B}$ in 5 cases, and exon 3 in 8 cases. For TP53, exon 5 could not be amplified in 6 cases, exon 6 in 10 cases, exon 7 in 7 cases, and exon 8 in 7 cases. In summary, amplification was not feasible for 27 exons of KLF6 in 15 cases and for 30 exons of TP53 in 17 cases.

\section{Results}

For KLF6, a total of 43 changes were found in different exons in the first PCR amplification, 42 in the DNA from FFPE samples, and 1 in the DNA from the frozen samples. In the second independent PCR reaction and sequencing, only five changes were found at exactly the same point. Four of them were confirmed in the FFPE specimens (4 of $42,9.5 \%$ ), whereas the only mutation detected in frozen tissue was also confirmed in the second PCR. The other changes ( 38 of $43,88.3 \%$ ) were not confirmed by the second PCR and sequencing reaction.

For TP53, 29 changes were detected in the first PCR amplification and sequencing reaction. Only 5 changes $(17.2 \%)$ were confirmed in a second independent PCR reaction and sequencing (5 of 29). No changes in TP53 were found in the frozen samples.

Thus, the overall frequency of artifacts was $36.9 \%$ (38/103) for KLF6 and 23.3\% (24/103) for TP53. All 
the changes not confirmed in a second PCR and sequencing reaction were found in FFPE cases.

The analysis of the four exons of KLF6 in the 103 cases revealed two different confirmed genetic mutations in five different tumors. The first change was a missense mutation detected only in one case and generating the transition $\mathrm{T} \rightarrow \mathrm{C}$ at codon 227 (Figure 1). This E227G mutation was located in exon
3 , and the tumor had a Gleason grade $=6$. This mutation has not been reported in previous studies. The other change was detected in exon 1 on the $5^{\prime}$-UTR region $(-4 \mathrm{C}>\mathrm{A}$ ) (Table 2 ). This change was detected in two independent PCR and sequencing reactions in four different tumors: two bone metastases, one found in a radical prostatectomy tumor with Gleason grade 8 , and one from a grade 6 . The

\section{KLF6}

Confirmed

mutation

WT sequence

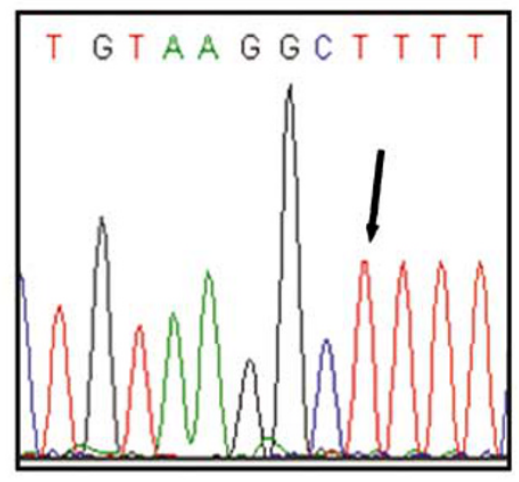

$1^{\text {st }} \mathrm{PCR}$

$E 227 G(A \rightarrow G)$

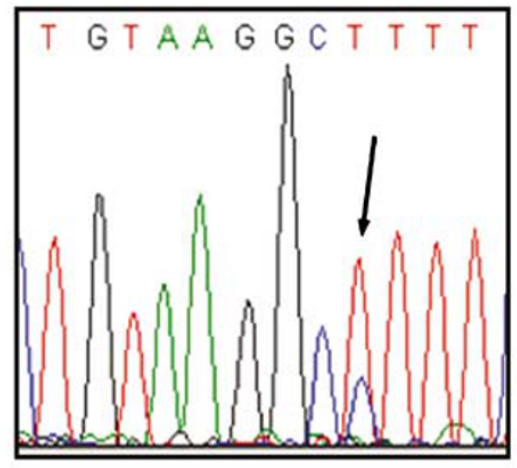

$2^{\text {nd } P C R}$

E227G $(A \rightarrow G)$

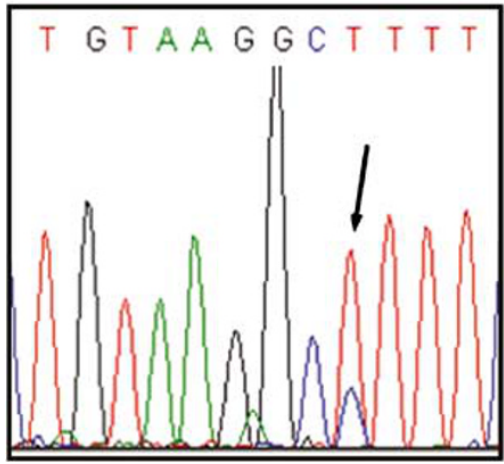

Non-confirmed

mutation

WT sequence

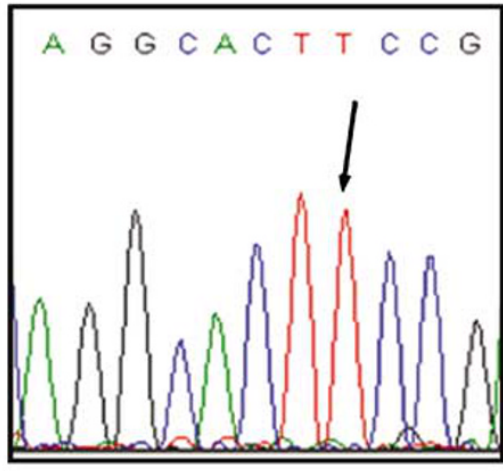

$1^{\text {st }} \mathrm{PCR}$

$\mathrm{F} 251 \mathrm{~S}(\mathrm{~T} \rightarrow \mathrm{C})$

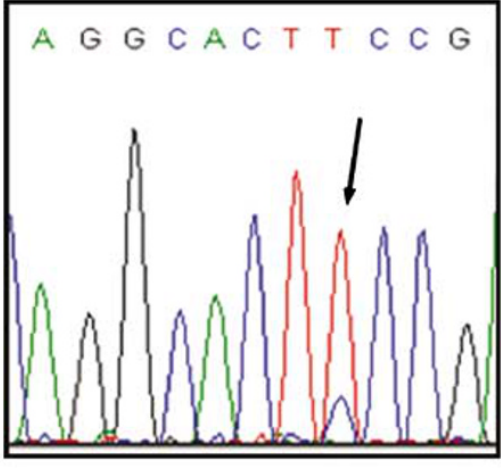

$2^{\text {nd }} \mathrm{PCR}$

WT sequence

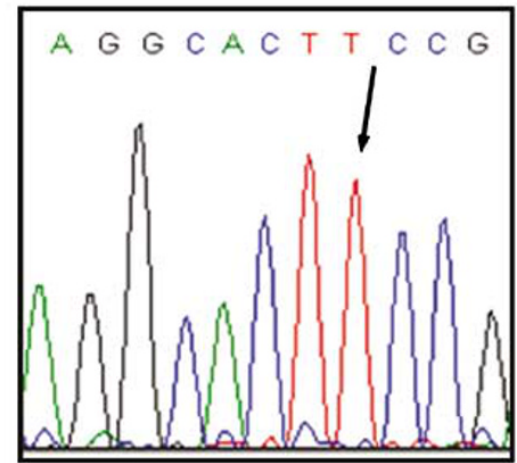

Figure 1 KLF6 mutation. The change is indicated by an arrow. There was a mutation in exon 3, transition $\mathrm{T} \rightarrow \mathrm{C}$ at codon 227 . 
Table 2 Summary of mutations found in $K L F 6$ and TP53

\begin{tabular}{rlllllll}
\hline Case & Gene & Exon & Genetic change & Type of mutation & Gleason score & Type of sample & FFPE/Fresh tissue \\
\hline 1 & KLF6 & Exon 3 & E227G & Missense & $3+3$ & Clinically significant tumor & FFPE \\
2 & KLF6 & $5^{\prime}$-UTR & $-4 \mathrm{C}>$ A & - & $3+3$ & Clinically significant tumor & Fresh tissue \\
3 & KLF6 & $5^{\prime}$-UTR & $-4 \mathrm{C}>$ A & - & $4+4$ & Clinically significant tumor & FFPE \\
4 & KLF6 & $5^{\prime}$-UTR & $-4 \mathrm{C}>$ A & - & - & Bone metastases & FFPE \\
5 & KLF6 & $5^{\prime}$-UTR & $-4 \mathrm{C}>\mathrm{A}$ & - & Bone metastases & FFPE \\
6 & TP53 & Exon 5 & L130H & Missense & $4+3$ & Clinically significant tumor & FFPE \\
7 & TP53 & Exon 5 & L130H & Missense & $4+4$ & Clinically significant tumor & FFPE \\
8 & TP53 & Exon 5 & L130H & Missense & $3+3$ & Autopsy & FFPE \\
9 & TP53 & Exon 6 & H214R & Missense & $4+5$ & Clinically significant tumor & FFPE \\
10 & TP53 & Exon 7 & Y234C & Missense & $3+4$ & Autopsy & FFPE \\
11 & TP53 & Exon 6 & P223L & Missense & - & DU145 & Cell line \\
12 & TP53 & Exon 8 & V274F & Missense & - & DU145 & Cell line \\
\hline
\end{tabular}

KLF6, Krüppel-like factor 6 .

exon $1-4 \mathrm{C}>\mathrm{A}$ change was previously reported in LAPC-3 and LUCaP49 xenografts by Chen et al. ${ }^{30}$ Bar-Shira et $a l^{32}$ described this alteration as a polymorphism, as it was detected in a control population and no statistical difference was found between prostate tumors and control samples.

No mutations in $K L F 6$ were detected in prostate cell lines PC3 and DU145. This is concordant with previous reports, ${ }^{31}$ except for Chen et $a 3^{30}$ who reported a mutation $-29 \mathrm{~A}>\mathrm{G}$ in the $5^{\prime}$-UTR of the PC3 cell line.

For TP53, three different mutations were identified in five different tumors. Three cases, with Gleason grades 6,7 , and 8 , respectively, had the transversion $\mathrm{T} \rightarrow \mathrm{A}$, resulting in the mutation $\mathrm{L} 130 \mathrm{H}$ in exon 5. The other two cases harbored the transition $A \rightarrow G$, resulting in the mutations $H 214 \mathrm{R}$ in a case with Gleason 9 (Figure 2) and Y234C in a case with Gleason 7 in exons 6 and 7, respectively (Table 2). All the mutations occurred at codons previously reported to be mutated in prostate cancer, as well as in other cancer types (www.iarc.fr). Finally, in 8 of the 13 frozen samples, in which exons 4-9 were also analyzed, the previously reported R72P $(\mathrm{G} \rightarrow \mathrm{C})$ polymorphism was detected (http://www.ncbi.nlm.nih.gov/SNP/ snp_ref.cgi?rs $=1042522$ ). Three cases were homozygous for that change and five were heterozygous.

In the prostate cancer cell line PC3, no TP53 mutations were detected, but in the DU145 cell line, two previously reported mutations were found.$^{54-57}$ They consisted of a transition $\mathrm{C} \rightarrow \mathrm{T}$ in codon 223 of exon 6 , generating the missense mutation $\mathrm{P} 223 \mathrm{~L}$ and a transversion $\mathrm{G} \rightarrow \mathrm{T}$ in codon 274 of exon 8 , resulting in the missense mutation $\mathrm{V} 274 \mathrm{~F}$.

The analysis of KLF6 and TP53 revealed one and five truly mutated tumors, respectively. The remaining changes, 38 in KLF6 and 24 in TP53, were artifacts. Most of these non-confirmed mutations involved the change of an adenine, suggesting that they could be artifactual mutations generated by Taq polymerase in the amplification process on FFPE samples.

\section{Discussion}

The described analysis of the four exons of KLF6 in the 103 cases revealed only one real mutation, which generated the transition $\mathrm{T} \rightarrow \mathrm{C}$ at codon 227 (E227G). The extensive study of exons 5-8 of TP53 showed three different mutations in five different tumors (L130H, H214R, and Y234C). The results obtained in the present study showed a very low frequency of mutation in $K L F 6(<1 \%)$ and also a low frequency in TP53 $(\approx 5 \%)$. The global rate was approximately $6 \%$, with 6 out of 103 cases harboring mutations. Most of the mutations occurred in cases with a Gleason score of 7 or more, indicating that although KLF6 and TP53 are not prevalent in prostate cancer, they tend to occur in tumors with high Gleason scores.

A polymorphism -4C $>$ A $5^{\prime}$-UTR was detected in $K L F 6$ in four (4\%) different cases. Finally, a polymorphism (R72P) was identified in TP53 in eight $(8 \%)$ tumors.

In the case of $K L F 6$ the results are in concordance with the most recently published papers on KLF6 mutations in prostate cancer, ${ }^{31,32}$ and they contrast with the much higher frequencies found in earlier studies. ${ }^{6,30}$ The rigorous methodological approach of our study strongly supports that many previously reported KLF6 mutations were probably artifacts.

It is surprising that, whereas in their initial paper Narla et $a l^{6}$ reported that about half of their tumors had mutations in the KLF6 gene, Chen et $a l^{30}$ subsequently found a lower frequency with only $15 \%$ mutations. Moreover, in the third published study, Mühlbauer et $a l^{31}$ found no KLF6 mutations in any of their 32 cases. Finally, using a different approach, Bar-Shira et $a l^{32}$ reported a frequency of mutations of less than $1 \%$ with only two mutations in 300 cases. Furthermore, all of the mutations identified in these studies were different. Only Mühlbauer et a ${ }^{31}$ confirmed mutations by performing two independent amplification PCRs. In contrast with the other studies, they only analyzed exon 2 . None of the other studies included methods to 
Confirmed

mutation

WT sequence

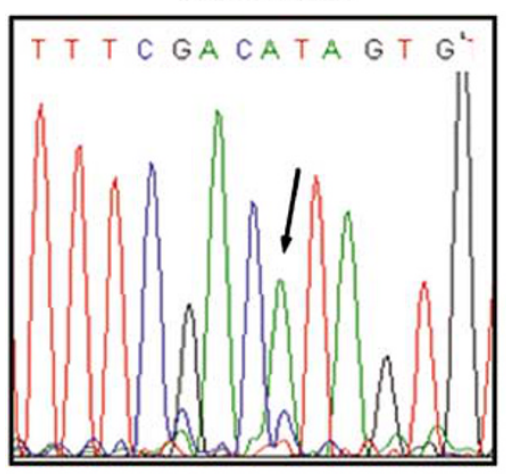

$1^{\text {st } P C R}$

$\mathrm{H} 214 \mathrm{R}(\mathrm{A} \rightarrow \mathrm{G})$

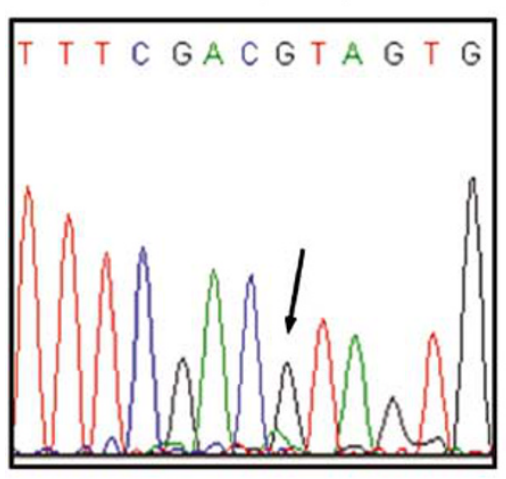

$2^{\text {nd }} P C R$

$H 214 R(A \rightarrow G)$

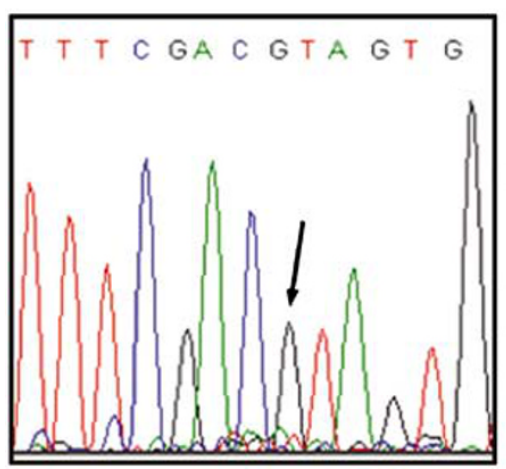

Non-confirmed mutation

WT sequence

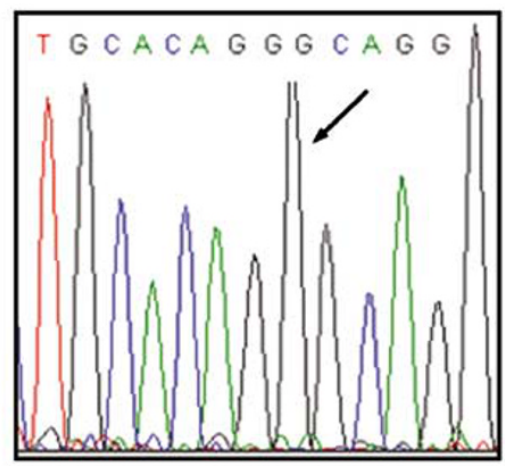

$1^{\text {st }} \mathrm{PCR}$

$\operatorname{H142R}(\mathrm{G} \rightarrow \mathrm{A})$

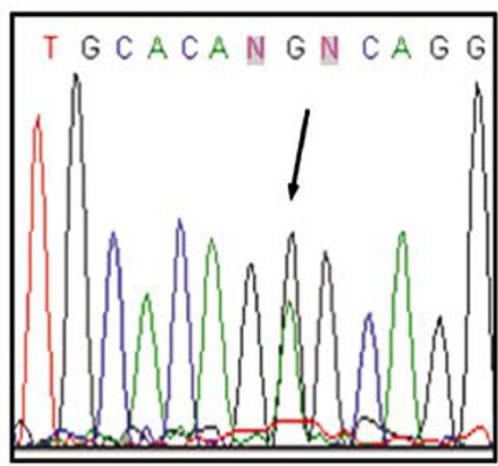

$2^{\text {nd }} P C R$

WT sequence

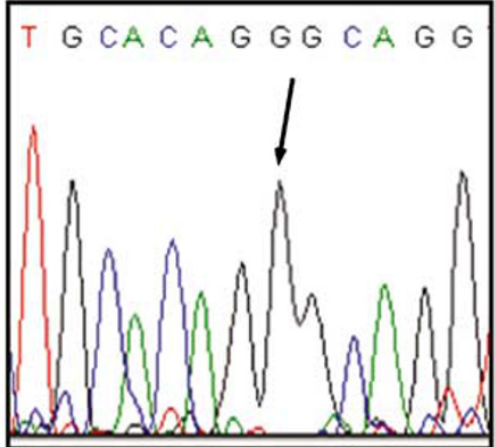

Figure 2 TP53 mutation. The change is indicated by an arrow. There was a mutation in exon 6, transition A $\rightarrow \mathrm{G}$ at codon 214 .

compensate for the possibility of artifacts being introduced by Taq polymerase. Although Chen et $a l^{30}$ repeated the single strand conformation polymorphism (SSCP) analysis in the cases with band shift in DNA, sequencing was performed only once for one PCR product.

Discrepancies in the frequency of KLF6 mutations have also been observed in HCC $^{10-13}$ (ranging between 0 and $15 \%$ ) and colorectal carcinoma ${ }^{14-18}$ (ranging between 0 and $44 \%$ ). Similar to prostate cancer, the first studies conducted on these other tumors indicated a high frequency of mutation, but this was not reproduced in subsequent reports. Song et $a l^{12}$ in a recent study with PCR reactions performed in triplicate experiments, did not find any KLF6 mutations in HCC. They related the controversial results in the previous series to genetic differences in the respective populations, PCR errors, or alternative splicing of $K L F 6$ due to a single polymorphism. 
In the case of TP53, the most recent articles do not deal with the frequency of mutation in this gene. During the first years of TP53 research in prostate cancer, many articles were published on this subject, and the reported frequency of mutation ranged from 3 to $42 \% .^{2,49}$ The IARC database (www.iarc.fr) reports a prevalence of $17 \%$. Some authors have postulated that TP53 mutations are rare in primary prostate cancer and that they are more common in prostate tumors with higher stage or grade, as well as metastases or androgen-independent tumors. ${ }^{2}$ Other authors argue that TP53 mutations are also a common event in early stages of prostate cancer development. ${ }^{58}$ Moreover, some papers report a strong association between prostate cancer bone metastases and a high frequency of TP53 mutations. ${ }^{2,59}$ In our study, no mutations were detected in metastatic tumors, but the number of metastatic cases was low. Meyers et a ${ }^{59}$ performed PCR-SSCP and immunohistochemistry to detect somatic DNA alterations, but they only sequenced one case. The sensitivity of the PCR-SSCP technique to detect true mutations is lower than that of other currently used methods, such as direct sequencing. Many authors have used immunohistochemistry to evaluate the TP53 gene mutation. ${ }^{2,59}$ It is thought that some mutations generate an abnormal protein that is not adequately metabolized and accumulates in the nucleus, allowing its immunohistochemical detection. In any event, immunohistochemical overexpression does not necessarily indicate gene mutation, as the protein accumulation may result from abnormalities in other genes involved in TP53 regulation and metabolism. ${ }^{2}$

In their paper, Mühlbauer et $a l^{31}$ reported a $12 \%$ frequency of TP53 mutations (3 out of 25). Their results are in keeping with the previous literature on the subject and are similar to the results of the present study.

A detailed methodological analysis of our results and those of the previous reports suggests that many of the discrepancies can be explained by technical issues. The fact that most molecular studies on prostate cancer use FFPE, whereas studies on other tumor types use frozen tissue sections as a source of DNA, is a crucial difference and must be examined with care. In the case of prostate cancer, the difficulties in retrieving fresh or frozen tumor tissue are obvious, as the gross appearance of prostate cancer is often very similar to that of normal, inflamed, or hyperplastic prostatic tissue. As a consequence, most molecular studies on prostate cancer are based on paraffin-retrieved material. This was the case in all four previous molecular studies on KLF6. The denaturation of DNA at AT-rich regions as a result of formaldehyde fixation, with the subsequent generation of free pyrimidine and purine residues, is well documented in the literature. $^{60-63}$ As a result of this phenomenon, Taq polymerase tends to insert adenosines when no template base is present, thus producing artificial mutations that are subsequently amplified throughout the PCR process. The number of errors introduced by Taq polymerase in fresh tissue samples is in the order of 1 in every $10^{5}$ base pairs, whereas in FFPE, it has been estimated at 1 in 500 . The chances of finding the same artifact in a second independent PCR are extremely low. Therefore, this second PCR and sequencing reaction is mandatory on all FFPE samples in which a sequence change has been identified. Our results further support this notion, as all the artifacts in our cases were detected in FFPE tissue, whereas no artifacts were detected in frozen samples.

Different fixation protocols have been used to prevent DNA integrity problems. ${ }^{64}$ However, none of the available fixatives ensures a complete preservation of DNA, and it is important to emphasize that the artifacts are induced not by fixation, but by Taq polymerase itself. In our retrospective study, we used one of the standard, buffered neutral formalin preparations. In order to exclude false-positive sequence mutations, we only accepted changes that were confirmed by two independent PCR amplifications. Interestingly, the initial frequency of mutation, including all detected changes, would have been around $42 \%$ for $K L F 6$ and $28 \%$ for $T P 53$, a rate that is similar to those found in the early reports on both genes. In our study, most of these nonconfirmed mutations (70\%) were transitions or transversions involving the addition of an adenine. The impact of artifactual changes on DNA sequence is also exemplified in other reports. As such, in a previous study on EGFR ${ }^{65}$ in lung cancer, many of the uncommon EGFR mutations found initially were discarded after performing multiple amplifications.

The different frequency of artifacts for $K L F 6$ and TP53 (36.9\% for KLF6 and $23.3 \%$ for TP53) can be explained by the different number of base pairs (bp) amplified in each gene, namely $1250 \mathrm{bp}$ for KLF6 and $850 \mathrm{bp}$ for TP53. Thus, the real proportion of artifacts introduced by Taq polymerase is very similar in both genes.

One of the suggested explanations for the discrepancies among the different authors relies on genetic differences in the populations studied, including diverse racial subgroups and variability in risk factors. But, in fact, this would be tenable only for very specific papers, as most of them have dealt with heterogeneous racial or geographical backgrounds.

It has recently been suggested that $K L F 6$ mutation may not be the only mechanism by which this gene could be involved in the pathogenesis of prostate cancer. DiFeo et al ${ }^{66}$ pointed out that there are three different KLF6-inactivating mechanisms: $\mathrm{LOH}$ and somatic mutation, hypermethylation of the promoter, and dysregulated alternative splicing. They suggested that only the first and third mechanisms would be involved. Recent reports by Narla et $a l^{7}$ support the notion that the loss of one KLF6 allele, even in the absence of somatic mutations in the 
remaining one, could be enough to contribute to cell proliferation and tumor development. The exact mechanism by which this would be effective is still unknown. Further studies are needed to investigate alternative mechanisms by which KLF6 could be involved in the pathogenesis of prostate cancer.

On the other hand, the low index of TP53 mutation could probably be assumed by the hypothesis that other molecules implicated in the p53 pathway, such as HMDM2, p14 ${ }^{\mathrm{ARF}}$ or PI3K, may be altered.

In conclusion, the present study strongly supports the notion that KLF6 as well as TP53 mutations are not frequent events in prostate cancer, although they may occur in cases with a high Gleason score. Thus, the mutations in these two genes are not crucial in the pathogenesis of prostate cancer. Our study also emphasizes the need for carefully controlling DNA quality and for confirming sequence changes with independent amplification and sequencing rounds, in order to obtain reliable results in mutational studies.

\section{Acknowledgements}

Grants FIS/Instituto de Salud Carlos III 965190005 and 06/1411, from the Ministry of Health of the Spanish Government and Support Grant 2006 from the Spanish Association Against Cancer (Barcelona Territorial Board).

\section{References}

1 Granado de la Orden S, Saá Requejo C, Quinatas Viqueira A. Epidemiological situation of prostate cancer in Spain. Actas Urol Esp 2006;30:574-582.

2 Dong JT. Prevalent mutations in prostate cancer. J Cell Biochem 2006;15:433-447.

3 Reynold MA, Kastury K, Groskopf J, et al. Molecular markers for prostate cancer. Cancer Lett 2007;249:5-13.

4 Kopper L, Tímár J. Genomics of prostate cancer: is there anything to translate? Pathol Oncol Res 2005;11: 197-203.

5 Bieker JJ. Krüppel like factors: three fingers in many pies. J Biol Chem 2001;276:34355-34358.

6 Narla G, Heath KE, Reeves HL, et al. KLF6, a candidate tumor suppressor gene mutated in prostate cancer. Science 2001;294:2563-2566.

7 Narla G, Kremer-Tal S, Matsumoto $\mathrm{N}$, et al. In vivo regulation of p21 by the Kruppel-like factor 6 tumorsuppressor gene in mouse liver and human hepatocellular carcinoma. Oncogene 2007;26:4428-4434.

8 Slavin DA, Koritschoner NP, Prieto CC, et al. A new role for the Kruppel-like transcription factor KLF6 as an inhibitor of c-Jun proto-oncoprotein function. Oncogene 2004;23:8196-8205.

9 DiFeo A, Narla G, Camacho-Vanegas O, et al. E-cadherin is a novel transcriptional target of the KLF6 tumor suppressor. Oncogene 2006;25:6026-6031.

10 Kremer-Tal S, Reeves HL, Narla G, et al. Frequent inactivation of the tumor suppressor Kruppel-like factor 6 (KLF6) in hepatocellular carcinoma. Hepatology 2004;40:1047-1052.
11 Boyault S, Herault A, Balabaud C, et al. Absence of KLF6 gene mutation in 71 hepatocellular carcinomas. Hepatology 2005;41:681-682.

12 Song J, Kim CJ, Cho YG, et al. Genetic and epigenetic alterations of the KLF6 gene in hepatocellular carcinoma. J Gastroenterol Hepatol 2006;21:1286-1289.

13 Pan XC, Chen Z, Chen F, et al. Inactivation of the tumor suppressor Kruppel-like factor 6 (KLF6) by mutationor decreased expression in hepatocellular carcinomas. J Zhejiang Univ Sci B 2006;7:830-836.

14 Reeves HL, Narla G, Ogunbiyi O, et al. Kruppel-like factor 6 (KLF6) is a tumor-suppressor gene frequently inactivated in colorectal cancer. Gastroenterology 2004;126:1090-1103.

15 Lievre A, Landi B, Cote JF, et al. Absence of mutation in the putative tumor-supressor gene KLF6 in colorectal cancers. Oncogene 2005;24:7253-7256.

16 Cho YG, Choi BJ, Kim CJ, et al. Genetic alterations of the KLF6 gene in colorectal cancer. APMIS 2006;114: 458-464.

17 Miyaki M, Yamaguchi T, Iijima T, et al. Difference in the role of loss of heterogosity at 10p15 (KLF6 locus) in colorectal carcinogenesis between sporadic and familial adenomatous polyposis and hereditary nonpolyposis colorectal cancer patients. Oncology 2007;71:131-135.

18 Mukai S, Hiyama T, Tanaka S, et al. Involvement of Kruppel-like factor 6 (KLF6) mutation in the development of nonpolypoid colorectal carcinoma. World J Gastroenterol 2007;29:3932-3938.

19 Cho YG, Kim CJ, Park CH, et al. Genetic alterations of the KLF6 gene in gastric cancer. Oncogene 2005;24: 4588-4590.

20 Chen HK, Liu XQ, Lin J, et al. Mutation analysis of KLF6 gene in human nasopharyngeal carcinomas. Ai Zheng 2002;21:1047-1050.

21 Vax VV, Gueorguiev M, Dedov II, et al. The kruppellike transcription factor 6 gene in sporadic pituitary tumours. Endocr Relat Cancer 2003;10:397-402.

22 Ito G, Uchiyama M, Kondo M, et al. Kruppel-like factor 6 is frequently down-regulated and induces apoptosis in non-small cell lung cancer cells. Cancer Res 2004;64:3838-3843.

23 DiFeo A, Narla G, Hirshfeld J, et al. Roles of KLF6 and KLF6-SV1 in ovarian cancer progression and intraperitoneal dissemination. Clin Cancer Res 2006;12:3730-3739.

24 Jeng YM, Hsu HC. KLF6, a putative tumor suppressor gene, is mutated in astrocytic gliomas. Int J Cancer 2003;105:625-629.

25 Kohler B, Wolter M, Blaschke B, et al. Absence of mutations in the putative tumor suppressor gene KLF6 in glioblastomas and meningiomas. Int J Cancer 2003; 105:625-629.

26 Montanini L, Bissola L, Finocchiaro G. KLF6 is not the major target of chromosome 10p losses in gliobastomas. Int J Cancer 2003;105:625-629.

27 Koivisto PA, Zhang X, Sallinen SL, et al. Absence of KLF6 gene mutations in human astrocytic tumors and cell lines. Int J Cancer 2004;111:642-643.

28 Camacho-Venegas O, Narla G, Teixeira MS, et al. Functional inactivation of the KLF6 tumor suppressor gene by loss of heterozygosity and increased alternative splicing in glioblastoma. Int J Cancer 2007;16: 1390-1395.

29 Teixeira MS, Camacho-Venegas O, Fernandez Y, et al. KLF6 allelic loss is associated with tumor recurrence and markedly decreased survival in head and neck squamous cell carcinoma. Int J Cancer 2007;9:1976-1983. 
30 Chen C, Hyytinen ER, Sun X, et al. Deletion, mutation, and loss of expression of KLF6 in human prostate cancer. Am J Pathol 2003;162:1349-1354.

31 Mühlbauer K-R, Gröne H-J, Ernst T, et al. Analysis of human prostate cancers and cell lines for mutation in TP53 and KLF6 tumour suppressor genes. Br J Cancer 2003;98:687-690.

32 Bar-Shira A, Matarasso N, Rosner S, et al. Mutation screening and association study of the candidate prostate cancer susceptibility genes MSR1, PTEN, and KLF6. Prostate 2006;66:1052-1060.

33 Hirasawa Y, Arai M, Imazeki F, et al. Methylation status of genes upregulated by demethylating agent 5-aza-2'-deoxycytidine in hepatocellular carcinoma. Oncology 2006;71:77-85.

34 Yamashita K, Upadhyay S, Osada M, et al. Pharmacologic unmasking of epigenetically silenced tumor suppressor genes in esophageal squamous cell carcinoma. Cancer Cell 2002;2:485-495.

35 Ito G, Uchiyama M, Kondo M, et al. Kruppel-like factor 6 is frequently down-regulated and induces apoptosis in non-small cell lung cancer cells. Cancer Res 2004;64:3838-3843.

36 Kremer-Tal S, Narla G, Chen Y, et al. Downregulation of KLF6 is an early event in hepatocarcinogenesis, and stimulates proliferation while reducing differentiation. J Hepatol 2007;46:645-654.

37 Kettunun E, Anttila S, Seppanen JK, et al. Differentially expressed genes in nonsmall cell lung cancer: expression profiling of cancer-related genes in squamous cell lung cancer. Cancer Genet Cytogenet 2004;149:98-106.

38 Beer DG, Kardia SL, Huang CC, et al. Gene-expression profiles predict survival of patients with lung adenocarcinoma. Nat Med 2002;8:816-824.

39 Glinsky GV, Glinskii AB, Stephenson AJ, et al. Gene expression profiling predicts clinical outcome of prostate cancer. J Clin Invest 2004;113:913-923.

40 Narla G, DiFeo A, Reeves HL, et al. A germline DNA polymorphism enhances alternative splicing of the KLF6 tumor suppressor gene and is associated with increased prostate cancer risk. Cancer Res 2005;65: 1213-1222.

41 Seppala EH, Autio V, Duggal P, et al. KLF6 IVS1 $-27 \mathrm{G}>\mathrm{A}$ variant and the risk of prostate cancer in Finland. Eur Urol 2007;4:1076-1081.

42 Spinola M, Leoni VP, Galvan A, et al. Genome-wide single nucleotide polymorphism analysis of lung cancer risk detects the KLF6 gene. Cancer Lett 2007; 251:311-316.

43 DiFeo A, Feld L, Rodriguez E, et al. A functional role for KLF6-SV1 in lung adenocarcinoma prognosis and chemotherapy response. Cancer Res 2007;4:965-970.

44 Cho YG, Lee HS, Song JH, et al. KLF6 IVS1 -27G/A polymorphism with susceptibility to gastric cancers in Korean. Neoplasma 2008;1:47-50.

45 Koivisto PA, Hyytinen ER, Matikainen M, et al. Kruppel-like factor 6 germ-line mutations are infrequent in Finnish hereditary prostate cancer. J Urol 2004;2:506-507.

46 Vogelstein B, Lane D, Levine AJ. Surfing the p53 network. Nature 2000;6810:307-310.
47 Osman I, Drobnjak M, Fazzari M, et al. Inactivation of the p53 pathway in prostate cancer: impact on tumor progression. Clin Cancer Res 1999;5:2082-2088.

48 Soussi T, Wiman TG. Shaping genetic alterations in human cancer: the p53 mutation paradigm. Cancer Cell 2007;12:303-312.

49 Gumerlock PH, Chi SG, Shi XB, et al. p53 abnormalities in primary prostate cancer: single-strand conformation polymorphism analysis of complementary DNA in comparison with genomic DNA. J Natl Cancer Inst 1997;1:66-71.

50 Selivanova G, Wiman KG. Reactivation of mutant p53: molecular mechanisms and therapeutic potential. Oncogene 2007;26:2243-2254.

51 Zambetti GP. The p53 mutation 'gradient effect' and its clinical implications. Cell Physiol 2007;213:370-373.

52 Vogelstein B, Lane D, Levine AJ. Surfing the p53 network. Nature 2000;16:307-310.

53 Zheng L, Wang F, Qian C, et al. Unique substitution of CHEK2 and TP53 mutations implicated in primary prostate tumors and cancer cell lines. Hum Mutat 2006;27:1062-1063.

54 Van Bokhoven A, Varella-García M, Korch C, et al. Molecular characterization of human prostate carcinoma cell lines. Prostate 2003;3:205-225.

55 Van Bokhoven A, Varella-Garcia M, Korch C, et al. Widely used prostate carcinoma cell lines share common origins. Prostate 2001;47:36-51.

56 Carroll AG, Voeller HJ, Sugars L, et al. p53 oncogene mutations in three human prostate cancer cell lines. Prostate 1993;23:123-134.

57 Isaacs WB, Carter BS, Ewing CM. Wild-type p53 suppresses growth of human prostate cancer cells containing mutant p53 alleles. Cancer Res 1991;51:4716-4720.

58 Downing SR, Russell PJ, Jackson P. Alterations of p53 are common in early stage prostate cancer. Can J Urol 2003;10:1924-1933.

59 Meyers FJ, Gumerlock PH, Chi SG, et al. Very frequent p53 mutations in metastatic prostate carcinoma and in matched primary tumors. Cancer 1998;83:2534-2539.

60 Williams C, Ponten F, Mobert C, et al. A high frequency of sequence alterations is due to formalin fixation of achival specimens. Am J Pathol 1999;155:1467-1471.

61 Hernandez S, Lloreta J. Manual vs laser micro-dissection in molecular biology. Ultrastruct Pathol 2006;30:221-228.

62 Pääbo S, Irwin DM, Wilson AC. DNA damage promotes jumping between templates during enzymatic amplification. J Biol Chem 1999;265:4718-4721.

63 Quach N, Goodman MF, Shibata D. In vitro mutation artifacts after formalin fixation and error prone translesion synthesis during PCR. BMC Clin Pathol 2004;265:4718-4721.

64 Gallegos Ruiz MI, Floor K, Rijmen F, et al. EGFR and K-ras mutation analysis in non-small cell lung cancer: comparison of paraffin embedded vs frozen specimens. Cell Oncol 2007;29:257-264.

65 Marchetti A, Felicioni L, Buttitta F. Assessing EGFR mutations. N Engl J Med 2006;2:526-528.

66 DiFeo A, Narla G, Hirshfeld J, et al. Roles of KLF6 and KSV1 in ovarian cancer progression and intraperitoneal dissemination. Clin Cancer Res 2006;12:3730-3739.

Supplementary Information accompanies the paper on Modern Pathology website (http://www.nature.com/ modpathol) 